BULL. AUSTRAL, MATH, SOC.

VOL. 29 (1984), 431.

\title{
CARDINALITY OF DISCRETE SUBSETS OF \\ A TOPOLOGICAL SPACE: \\ CORRIGENDUM
}

\author{
David B. Gauld and M.K. Vamanamurthy
}

Theorem $I$ and Corollary $I$ of the original paper [BulZ. Austral. Math. Soc. 25 (1982), 99-101] are false unless, for example, we assume the Generalised Continuum Hypothesis. The proof of Theorem 1 correctly shows that $\exp (|C|) \leq \exp (|D|)$ but one cannot then deduce that the cardinality of $C$ is at most that of $D$. All one can deduce is that the cardinality of $C$ is less than $\exp (|D|)$.

Department of Mathematics and Statistics, University of Auckland, Private Bag, Auck land, New Zealand.

Received 8 February 1984.

Copyright Clearance Centre, Inc. Serial-fee code: 0004-9727/84 $\$$ A2.00 +0.00 .

431 